RAUL FIKER

\title{
Interpjetanão alegósica de
}
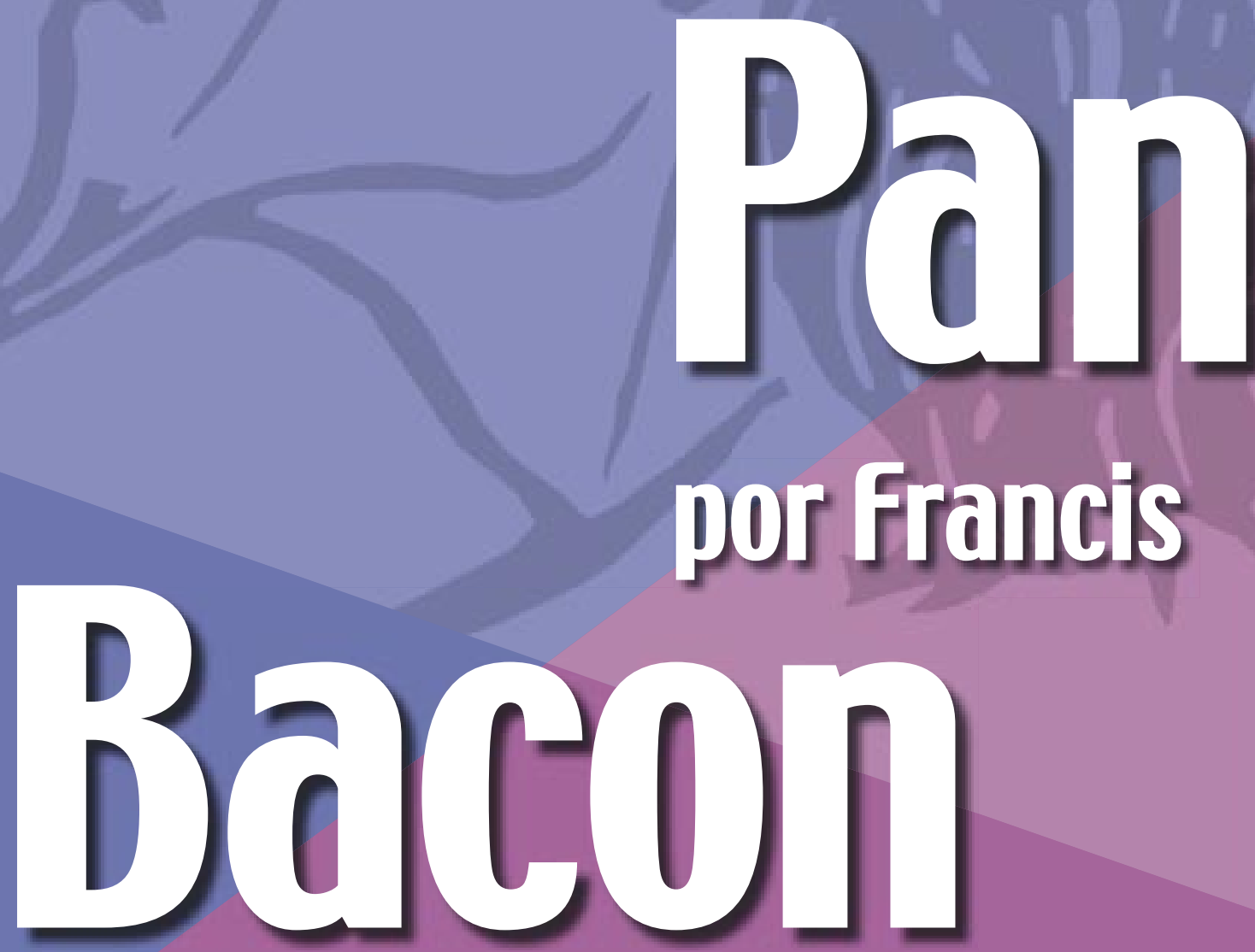

RAUL FIKER

é professor da

Unesp-Araraquara

e autor de,

entre outros,

Vico: o Precursor

(Moderna). 

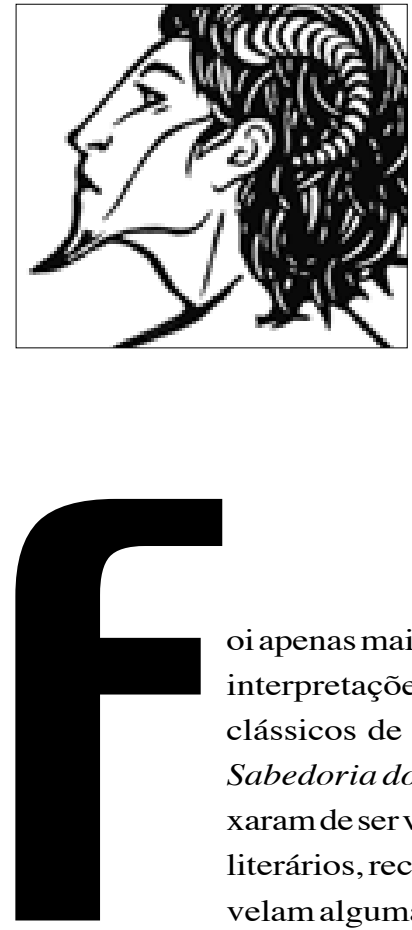

oi apenas mais recentemente que as interpretações alegóricas de mitos clássicos de Francis Bacon em $A$ Sabedoria dos Antigos (1609) deixaram de servistas comoexercícios literários, reconhecendo-se que revelam algumas de suas concepções científicas, filosóficas e políticas que nem sempre são explicitadas ao longo de sua obra. O presente artigo procura dar resumidamente um exemplo típico através de sua interpretação do mito de Pan. Essa temática encontra-se desenvolvida em $O$ Conhecer o Saber em Francis Bacon (Fiker, 1996).

É através da interpretação do mito de Pan - Pan Sive Natura (no De Sapientia Veterum, ampliada em 1623 no De Augmentis Scietiarum) que Bacon coloca sua posição sobre o naturalismo materialista. No Advancement of Learning (Works, III, 354), Bacon se remete à doutrina "referente à contextura e configuração das coisas". Sua interpretação do mito de Pan ilustra a primeira, ao passo que a de Cupido-Cupido Sive Atomus - ilustra a segunda.

Bacon parafraseia o mito iniciando pelo significado alegórico, como ponto pacífico: os antigos, sob a figura de Pan, descreveram toda a natureza, deixando em dúvida apenas a origem. Uns o fazem nascer de Mercúrio, outros, de uma relação promíscua que Penélope teria tido com todos os pretendentes. Mas essa segunda versão é descartada, pois Pan é um dos deuses mais antigos, tendo existido muito antes de Ulisses; e Penélope foi venerada na Antiguidade justamente por sua castidade matronal. Há ainda uma terceira suposta gênese: ele seria filho de Jove e Hybris, a insolência. Qualquer que tenha sido seu nascimento, diz-se que ele tinha como irmãs as Parcas. Pan era representado com cornos que se elevavam até o céu, áspero e veloso em todo o corpo e com a barba particularmente longa. Era biforme: humano na parte superior, animal na inferior, com patas caprinas. Como emblemas de seu poder, trazia na mão esquerda uma gaita de sete tubos; na mão direita um cajado de pastor, curvo e arredondado na parte superior, e vestia um manto curto de pele de pantera. Eram-lhe atribuídos os seguintes poderes e prerrogativas: era deus dos caçadores, dos pastores, de todos os camponeses, protetor dos montes, além de núncio dos deuses ao lado de Mercúrio. Líder e guia das ninfas, fazia-se acompanhar dos sátiros e, mais velhos que estes, dos silenos. Tinha ainda o poder de produzir certos terrores, especialmente vãos e supersticiosos, chamados "pânicos". Não há lembrança de muitos feitos seus, a não ser de quando desafiou Cupido para lutar sendo derrotado, e de quando conseguiu prender com uma rede o gigante Tifão. Conta-se também que, quando Ceres, triste com o rapto de Proserpina, penetrou no bosque e todos os deuses foram em seu encalço, Pan a encontrou por acaso enquanto caçava. Ele ousou também disputar com Apolo uma competição musical, sendo considerado vencedor pelo juiz, Midas, que por isso ficou com orelhas de asno, as quais ocultava de todos. Praticamente nada se diz dos amores de Pan, sendo-lhe atribuída apenas a paixão por Eco, considerada também sua esposa, e pela ninfa Syrinx, por quem se enamorara ao ser atingido por uma seta vingadora de Cupido. E não teve filhos, exceto uma hipotética filha, Iambe, que deveria divertir os hóspedes com historietas burlescas e que ele teria tido com Eco.

A paráfrase do mito, como foi diversas vezes demonstrado ${ }^{1}$, é quase tomada literalmente por Bacon de Comes (1567, Mythologie, Sive Explicationis Fabularum Libri Decem, Veneza, s. ed., v.6). Segundo mostra Jardine (1974, p. 181), os três detalhes da narrativa de Bacon que não se 
encontram no capítulo dedicado a Pan em Comes estão em outros três capítulos: em III, 6, "De Parcis", Comes identifica as Parcas como irmãs de Pan; em IX, 15, "De Mida", Comes se refere à disputa entre Pan e Apolo; em III, 16, "De Proserpina”, ele identifica Iambe com a filha de Pan e Eco.

Em relação aos relatos tradicionais, Bacon omite a consorte de Mercúrio na concepção de Pan, que, segundo alguns, era Dryope, filha de Dryops e neta de Apolo, ou a ninfa Oeneis; ou ainda Amaltéia, a Cabra, ou mesmo Penélope - cuja "castidade matrônica”, segundo Graves (1975, vol. 2, pp. 373-4), apoiando-se em Servius, Pausânias, Cícero, Tzetzes e outros, não era uma unanimidade clássica. Quanto à vida amorosa de Pan, a tradição lhe atribui ainda a sedução de diversas ninfas além de Eco e de Eufreme, preceptora das Musas. Bem como a tentativa de violar Pitys e uma orgia com todas as Mênades. Ainda nesse âmbito, Bacon não menciona a sedução de Selene. Quanto à sua descendência constam também Lynx - com Eco - e Crotus, o Arqueiro no Zodíaco - com Eufeme (Graves, 1975, vol. 1, pp. 101-3). Tampouco é mencionada, na versão de Bacon, a suposta morte de Pan - ver o verbete Pan na Oxford Companion to Classic Literature e em Graves (1975).

Eis a interpretação de Bacon: Pan, como o próprio nome diz, representa a universalidade das coisas ou a natureza. Seu nascimento de Mercúrio significa que provém da palavra divina; se do "intercurso promíscuo" de Penélope com os pretendentes, sua origem está na mistura e confusão das sementes das coisas. A terceira sugestão, contudo, a que o aponta como filho de Jove e Hybris, trata do estado do mundo depois da queda de Adão, sendo exposto à morte e à corrupção. Essa terceira hipótese demonstra que os gregos devem ter sido influenciados pelos mistérios hebreus, que os alcançaram através dos egípcios. Mas as três versões podem ser acolhidas como verdadeiras, segundo a distinção dos fatos e das épocas, pois é verdade que esse Pan que intuímos, contemplamos e honramos mais do que deveríamos saiu do verbo divino mediante a matéria confusa e pela interposição da prevaricação e da corrupção. A natureza e o destino das coisas são postos como irmãos, porque a cadeia das coisas naturais traz consigo o nascimento, a duração e a morte, a depressão e a proeminência, a desgraça e a fortuna.

Os cornos com que o mundo é representado são mais grossos nas bases indicando uma forma piramidal da natureza. Os indivíduos são infinitos e se agrupam em espécies, que também são múltiplas e por sua vez se agrupam em gêneros, cujo número vai diminuindo conforme se dirige aos gêneros mais universais, de modo que a natureza parece querer encontrar-se enfim na unidade. E é significativo o fato de os cornos de Pan chegarem até o céu, pois o cimo da natureza, as ideias universais alcançam de certa forma a Deus, assim como se passa da metafísica à teologia natural.

O corpo da natureza é veloso devido aos raios das coisas, que são como os pelos da natureza, e quase todas as coisas são mais ou menos radiantes; como se observa na

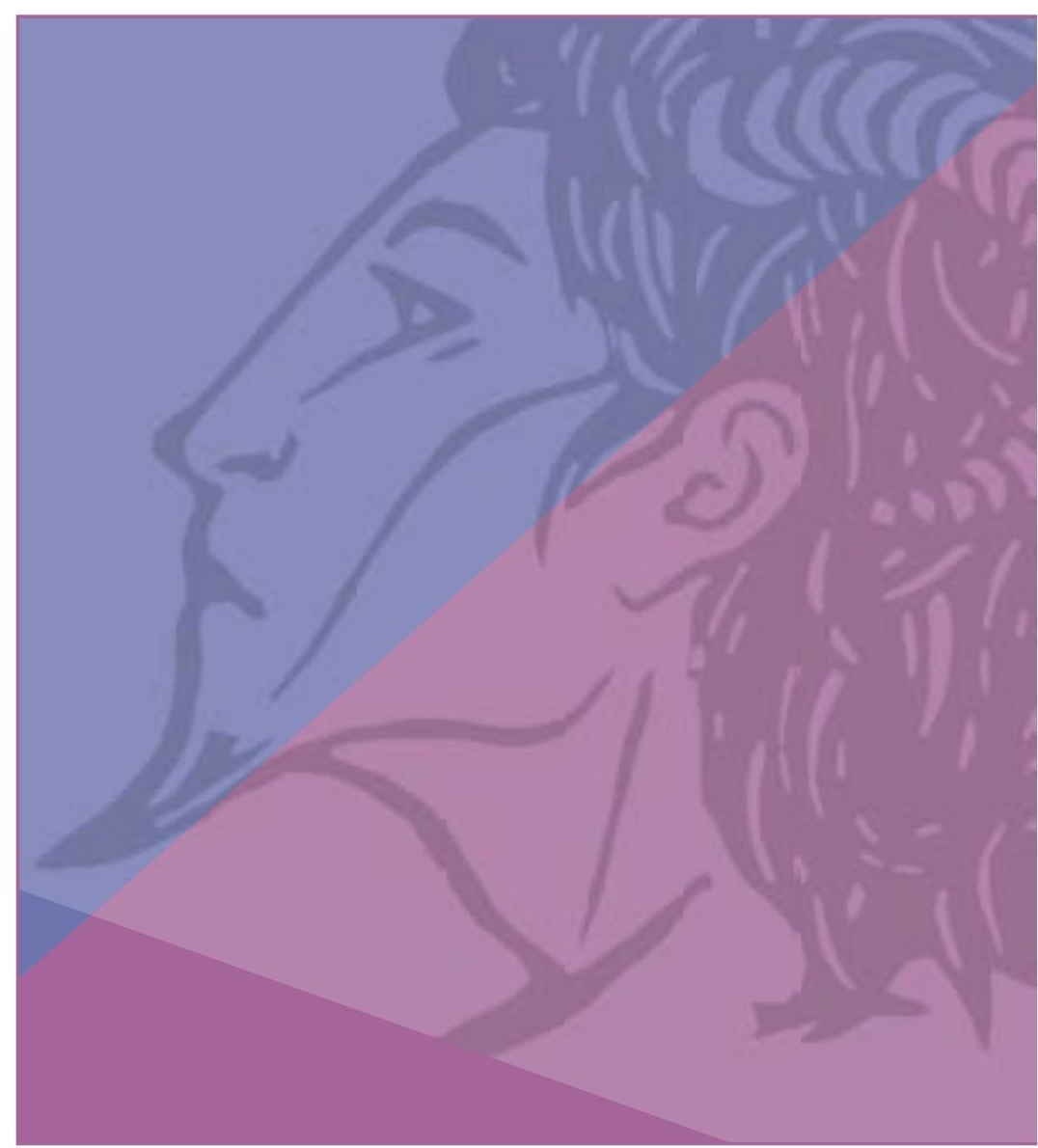



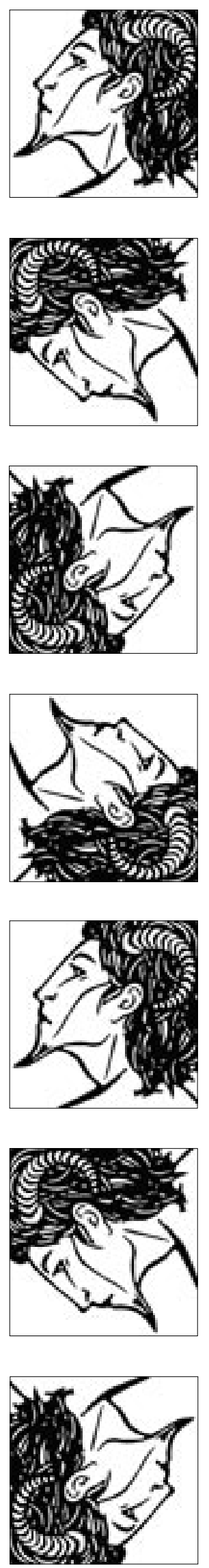

faculdade da visão e em qualquer operação a distância, pois qualquer coisa que opera a distância deve emitir raios. A barba é a parte mais pronunciada de $\mathrm{Pan}$, pois os raios dos corpos celestes operam e penetram mais de longe. Assim, o sol, quando sua parte superior está obscurecida por uma nuvem, emite os raios pela parte inferior e parece ter barba. $\mathrm{O}$ corpo é biforme devido à natureza diversa dos corpos superiores e inferiores, os primeiros representados na parte humana, os segundos, na forma de animal. A descrição das partes do corpo exprime a participação da espécie, pois nenhuma natureza é simples, mas sim formada de duas partes: o homem tem algo de animal, o animal algo de planta, a planta algo de inanimado. As patas caprinas indicam o movimento ascendente dos corpos terrestres às regiões do ar e do céu, pois o equilíbrio da cabra nas montanhas remete à gravitação das coisas no globo inferior.

Dos símbolos que traz nas mãos, a gaita (ou flauta) representa a harmonia das coisas, enquanto o cajado indica as vias da natureza, umas diretas, outras não; assim, sua parte posterior é encurvada porque todas as obras da natureza divina no mundo correm por vias tortuosas, como o Vanda de José no Egito. Também no governo humano, os benefícios para o povo não são obtidos diretamente. As vestes de Pan são uma pele de leopardo porque suas manchas representam o céu coberto de estrelas, o mar de ilhas, a terra de flores, o que significa que as coisas, embora singulares, são variegadas em sua própria superfície.

O ofício de Pan é a caça porque todo ato natural, todo movimento ou processo não é outra coisa que uma caçada. As artes e ciências vão à caça de suas obras, as ações dos homens perseguem suas finalidades e todas as coisas da natureza vão em busca de sua presa, que é seu alimento, ou de prazeres, que são sua recreação. Pan é o deus dos camponeses - porque estes, mais que quaisquer outros, vivem segundo a natureza-e preside especialmente os montes porque é do alto destes que a natureza mais esplendidamente se oferece à vista. E que
Pan seja núncio dos deuses é alegoria divina, pois logo depois do verbo de Deus, a própria imagem do mundo é índice da sabedoria e potência divinas. Em torno de Pan estão as ninfas, que são as almas, e os sátiros e silenos, ou a velhice e a juventude, etapas de todas as coisas.

A ideia do terror pânico se refere ao fato de a natureza ter produzido em todos os viventes sentimentos de medo destinados a preservar a vida mas, ao lado dos temores saudáveis, provocou também outros que são inúteis, como as superstições, sobretudoem tempos difíceis e incertos.

No que toca ao desafio de Cupido, ele significa que a matéria tem uma certa inclinação a dissolvero mundo e retornar ao Caos primordial, mas a mais forte concórdia das coisas, simbolizada por Amor ou Cupido, submete a malícia e a violência da matéria. O episódio da captura de Tifão nas redes também se refere aos vastos e insólitos movimentos da matéria. Adescoberta de Ceres, por quem todos os deuses procuravam em vão, significa que para descobertas úteis os filósofos abstratos (simbolizados pelos deuses maiores) são de menos ajuda que Pan, ou a experiência e o conhecimento da natureza. O episódio da competição musical ensina que há uma dupla harmonia, similar à música: a da providência divina e a razão humana. O governo do mundo e das coisas naturais bem como os desígnios mais íntimos de Deus são estranhos e difíceis de entender, e essa ignorância é simbolizada pelas orelhas de asno.

Que a vida amorosa de Pan se resuma basicamente em seu matrimônio com Eco é porque amar é querer algo, e Pan, representando o universo da natureza, não carece de nada. Eco representa a verdadeira filosofia, pois seu discurso consiste em repetir e ecoar, reproduzir fielmente a voz da natureza, sem nada acrescentar de seu a ela. Finalmente, que o mundo não tenha prole se refere à sua perfeição e autossuficiência, e nesse sentido Iambe, às vezes erroneamente tomada como filha de Pan, é um símbolo dessas doutrinas vãs que vagam pelo mundoe das quais muito se fala, que permanecem infrutíferas e que, embora sejam às vezes agradáveis, são no 
mais das vezes aborrecidas e inoportunas.

No estudo acima citado, Jardine procura mostrar que essa interpretação também traz sinais inquestionáveis da influência de Comes e outros mitógrafos, embora reconheça sua consistência. A interpretação naturalista de Pan é tradicional. Para Apolodoro e Cornutus, por exemplo, as pernas velosas e o busto humano do deus se referem à vegetação da parte inferior da terra e ao éter, sede do princípio diretor Também em Macróbio (Saturnais, I, 22) se encontra esse tipo de interpretação, no caso identificando Pan ao sol. Vamos procurar nos ater às colocações que, no mais das vezes específicas de Bacon, referem-se a aspectos de seu próprio pensamento.

Depois de identificar Pan à natureza Bacon situa sua origem como nascido da Palavra de Deus e da matéria - criada por Deus - para a confusão da qual a Queda contribuiu. Que o mundo se origine nessa mistura confusa das sementes das coisas, por outro lado, é algo que vai ao encontro da teoria baconiana de um substrato material no qual as formas são impressas ${ }^{2}$. $\mathrm{Na}$ descrição dos cornos de Pan, que atingem o céu, representando a pirâmide do universo, Bacon fala de uma passagem (transitus) da metafísica à teologia, o que se afasta de sua concepção de divisão clara entre ambas. Referindo-se a essa passagem, F. Anderson (1971, p. 61) diz que os cumes ou formas universais da natureza alcançam "de certo modo, mas apenas de certo modo, Deus. Os cumes das coisas não manifestam a natureza real nem a vontade íntima de Deus, contudo estas são reservadas à Palavra revelada”. É a concepção de Bacon, mas o texto não é assim explícito; pelo contrário, diz: "cum summitates natura sive Idea universales etians ad divina quodammodo pertingant", e a ênfase pode ser dada tanto para quadammodo como para pertingant.

A interpretação da forma meio homem e meio bode do deus, indicando a diferença entre os corpos celestes e terrestres, especifica, para P. Rossi (1968, p. 259), que essa diferença não é, como estipula Aristóteles, uma diferença de espécie. O Pan deus da caça também traz outra recorrência em Bacon: todo processo natural, bem como as ciências e as artes, constitui formas de caça. Uma das etapas do método baconiano de pesquisa científica chama-se justamente Venatio Panis. No episódio do encontro de Ceres, trata-se novamente da crítica da filosofia abstrata, vista também a propósito do mito de Prometeu e que integra a reforma baconiana do conhecimento. A mesma crítica se encontra, finalmente, no casal Pan/Eco, isto é, no discurso que reproduz fielmente a natureza como sendo a verdadeira filosofia, escrita como se ditada pelo próprio mundo, sem nada acrescentar de seu. Esse último aspecto - que pertence exclusivamente à interpretação baconiana e diz respeito à sua própria filosofia - é, na conclusão da fábula, mais uma vez enfatizado na figura de Iambe, com seu discurso infrutífero, que pode às vezes ser divertido mas termina sempre por aborrecer.

\section{BIBLIOGRAFIA}

ANDERSON, F. The Philosophy of Francis Bacon. New York, Octagon, 1971.

FIKER, R. O Conhecer e o Saber em Francis Bacon. São Paulo, Nova Alexandria/Fapesp, 1996.

GRAVES, Robert. The Greek Myths. Londres, Penguin, 1975.

JARDINE, L. Francis Bacon, Discovery and the Art of Discourse. Cambridge, Cambridge Univ. Press,

1974 , pp. 180 e segs.

ROSSI, P. Francis Bacon, from Magic to Science. Londres, R\&KP, 1968.

Vera esse propósito,Jardine (1974, p. 184) e também a versão ampliada do mito no De Augmentis, em que essa referência está mais explíita. 